\title{
SUJEITOS “TRANSVIADOS": A SITUAÇÃO DO ATENDIMENTO DE SAÚDE DAS PESSOAS TRANS EM ARAGUAÍNA-TO.
}

\author{
Lídio Fernando Vieira Barros ${ }^{1}$
}

Resumo: Este trabalho aborda a efetividade da Política Nacional de Saúde Integral LGBT quanto ao atendimento de pessoas trans em Araguaína-TO. O desenho do atendimento de saúde nas Unidades Básicas de Saúde desse segmento constitui um desafio acadêmico pela complexidade da questão que envolve Estado, Município e União em regime de corresponsabilidade. A análise proposta se refere ao respeito do nome social dessas pessoas quando precisam do SUS para acompanhamento da hormoneoterapia e a necessidade de atenção médica multidisciplinar, principalmente, quando é manifestada pelo usuário/a necessidade da cirurgia de transgenitalização.

Palavras- chave: Efetividade. Trans. SUS.

Abstract: This paper discusses the effectiveness of transgender people care in Araguaína-TO developed by LGBT
National Policy of Integral Health. The format of health care in the Basic Health Units of this segment constitutes an academic challenge because of the complex relation of co-responsibility among State, City and Union departments. This proposal concerns the social name of these people when they need the SUS to follow the hormone therapy and when they need multidisciplinary medical care, especially when he or she manifests the necessity of transgenitalization surgery.

Keywords: Effectiveness. Trans. SUS.

\section{Introdução}

Sujeitos "TRANSviados" é uma alusão a sigla LGBT que de acordo Judith Butler (2001) são sujeitos que escapam da heteronormatividade, ou seja, subvertem o que é designado socialmente a elas que é a linearidade entre sexo biológico- gênero- orientação sexual.

\footnotetext{
${ }^{1}$ Graduado em geografia, pós graduado em Gestão Pública e sociedade; Mestrando em estudos de Cultura e Território (PPGCULT) Universidade Federal do Tocantins.
} 
Assim, "TRANS" em caixa alta designa as pessoas travestis e transexuais e, "viados" em minúsculo significa a designação popular das pessoas de todas as orientações sexuais e identidade de gênero que não são a norma.

Portanto, viado, sapatão, xibungo, boiola, etc.; são adjetivos usados para estigmatizar, ofender e discriminar, gays, lésbicas, bissexuais, travestis e transexuais.

Nesta concepção, esse título é simbólico e crítico.

O debate do tema da Transexualidade é um dos fenômenos que tem projetado visibilidade nos campos, médico, bioético e jurídico, necessitando de regulação legal e de políticas públicas que garantam a cidadania plena das pessoas travestis e transexuais nos diversos âmbitos da vida (PACHECO et al., 2013).

A marginalização dos (as) transexuais e travestis no Brasil advêm da necessidade de políticas públicas e arcabouço jurídico específico para lidar com as demandas dessa população, como exemplo, a alteração do prenome e gênero no registro civil que ainda é jurisprudencial, fato que causa imenso transtorno e expõe esses indivíduos a situações vexatórias e constrangedoras.

De acordo com Guacira Lopes Louro (2008) os processos de exclusão social experimentados pelo (as) transexuais e travestis decorrem da discriminação/preconceito advindos da discordância na linearidade entre o sexo biológico-gênero-orientação sexual.

Portanto, pessoas que nascem com genitália masculina automaticamente são lidas como homens e as com vagina como mulheres e "é atribuído a elas significados culturais nomeando o corpo em um caráter imutável, a-histórico e binário (BUTLER apud LOURO, 2008)".

Na concepção de Bader Sawaia (2001) exclusão social "é o processo sócio histórico, que se configura pelo recalcamento em todas as esferas da vida social, mas, é vivido como necessidade do eu, como sentimentos, significados e ações".

Neste espectro o conceito de exclusão social para esta população parece significar a negação ao direito de ter reconhecida plenamente sua identidade de gênero ou vive-la de forma clandestina. 
Para (SAWAIA apud

MARTINS, 1997, p. 48) quando se fala em "nova exclusão", atribui-se ao "excluído" o fato de estar em situação de carência material, mas, sobretudo, “[...] ser aquele que não é reconhecido como sujeito, que é estigmatizado, considerado nefasto ou perigoso à sociedade”.

Sujeitos que transgridam as normas em relação ao corpo e os papéis sociais de gênero "vivem perigosamente e, estão expostos a sanções, reformas e exclusões (LOURO, 2008, p. 16)”.

Este artigo trata da Política Nacional de Saúde Integral LGBT que representa um norteamento para as ações de saúde direcionadas a população LGBT nos Estados e municípios de acordo com os anseios expressos no Programa Brasil sem Homofobia sob a coordenação da Secretaria de Direitos Humanos da Presidência da República (SDH/PR) que, hoje em dia, compõe o Programa Nacional de Direitos Humanos.

Os dados coletados para realização deste estudo têm como base as concepções de (GIL 2007 apud SOUSA, 2014, p. 28) que "a pesquisa exploratória contribui para tornar o objeto mais explícito bem como, ajuda a
70

problematizar questões de interesse do pesquisador".

No primeiro momento foi realizado levantamento bibliográfico e $a$ posteriori entrevistas com o públicoalvo envolvido mulheres transexuais, travestis e homens transexuais.

De acordo com (GODOY 1995 apud SOUSA, 2014, p. 28) a pesquisa qualitativa não é aquela realizada através de números, gráficos, tabelas ou ainda de questionários objetivos, mas sim, de "dados coletados que aparecem sob a forma de transcrições de entrevistas, anotações de campo, fotografias, videoteipes, desenhos e vários tipos de documentos".

Neste tipo de pesquisa a proximidade do pesquisador é crucial para o desenvolvimento satisfatório do estudo, tendo em vista que ele também é parte integrante do estudo.

A escolha desse tema se espraia na vivência da transexualidade e na falta de atendimento de saúde específico para o segmento TT [travestis e transexuais] no Estado do Tocantins.

A coleta de dados foi realizada através de entrevistas utilizando aparelhos gravadores de áudio e na aplicação de questionários semiabertos. 
ISSN | 2179-7137 | http://periodicos.ufpb.br/ojs2/index.php/ged/index

Posteriormente, foi realizada a transcrição das falas na íntegra selecionadas de acordo com a pertinência deste estudo.

Este trabalho se justifica pela importância do tema que esboça uma série de violações de direitos, garantidos a todos os cidadãos brasileiros na Constituição Federal (BRASIL, 1988) e que a população LGBT especialmente ás travestis e as/os transexuais são negados cotidianamente.

O direito à saúde é algo fundamental a manutenção e integridade das pessoas, assim como, o direito à vida são preceitos invioláveis na Constituição Federal (BRASIL, 1988).

É importante frisar, no que tange a população TT [travestis e transexuais] as especificidades do atendimento de saúde são diferentes das que demandam a população LGB [lésbicas, gays e

\footnotetext{
${ }^{2} \mathrm{O}$ conceito de identidade de gênero faz parte dos estudos Queer (JANOSE, 1996) e diz respeito às performances de gênero contrárias as impostas socialmente ao sexo biológico originário. Assim, pessoas transexuais e travestis, possuem características físicas e comportamentais do gênero oposto ao do seu nascimento. De maneira que, essas pessoas possuem performances de masculinidades e feminilidades construídas e não originárias da biologia

3 Orientação sexual diz respeito ao desejo e atração por pessoas do mesmo sexo, do sexo oposto e ainda dos dois sexos.
}

bissexuais] por se tratar de identidade de gênero ${ }^{2}$ e não de sexualidade ${ }^{3}$.

Neste espectro, no Brasil, a base legal para o desenvolvimento de políticas públicas em torno da transexualidade se fundamenta na compreensão das ciências psi (psiquiatria, psicologia e psicanálise) onde

a transexualidade constitui uma desordem mental; para alguns autores que discutem as experiências trans, em especial nas ciências sociais e humanas e na saúde coletiva, estas são vivências que colocam em questão as normas de gênero que regem nossos conceitos de sexo, gênero e, no limite, de humano (BENTO, 2006).

Porém, esta interpretação patologizante da transexualidade vem gerando debates acalorados em movimentos de nível internacional pela despatologização ${ }^{4}$.

\footnotetext{
${ }^{4}$ A transexualidade no Brasil é interpretada como uma desordem mental denominada "disforia de gênero" ou transtorno de identidade sexual, porém, para outras ciências como as humanas e a Saúde coletiva "essas são experiências que colocam em cheque as normas de gênero que regem nossos conceitos [...] no limite de humano" existe um movimento mundial em prol da despatologização da transexualidade a nível mundial como no caso da Argentina onde existem leis de identidade de gênero no qual a pessoa não precisa mais utilizar a via judicial para retificação do nome e gênero nos documentos e é atendida na rede de saúde em sua especificidade. (ALMEIDA e MURTA, 2013).
} 
O objetivo geral desse trabalho foi analisar no município de AraguaínaTocantins a situação da implementação da Política Nacional de Saúde Integral de Lésbicas, Gays, Bissexuais, Travestis e Transexuais, instituída pela Portaria $\mathrm{n}^{\circ}$ 2.836, de $1^{\circ}$ de dezembro de 2011 .

Os objetivos específicos foram: realizar pesquisa qualitativa através de questionários com a população de travestis e transexuais e com os gestores responsáveis pela execução dessa política a nível municipal; Compreender se o acesso à saúde integral dessas pessoas no âmbito do SUS em Araguaína-TO está satisfatório, quanto ao respeito do nome social e acompanhamento da hormoneoterapia já que a modalidade hospitalar para realização da transgenitalização não ocorre no Estado.

\section{Breve histórico do movimento LGBT brasileiro e a luta por saúde.}

A luta da população LGBT por visibilidade e respeito na sociedade brasileira se remonta a segunda metade do século XX mais especificamente em 1970.
A população LGBT terá suas pautas organizadas na década seguinte em torno da difusão da AIDS como epidemia fortemente vinculada aos gays. Na década de 1980 havia no Brasil a necessidade de ampliação das ações em saúde voltadas para o combate à disseminação do HIV/AIDS e um dos segmentos vulneráveis eram os gays e travestis.

De maneira que as organizações e movimentos sociais voltados para a defesa e promoção dos direitos LGBT tiveram que empenhar-se conjuntamente com o Ministério da Saúde para diminuir os índices de HIV/AIDS nesta população.

Neste contexto, o movimento homossexual brasileiro começa a ampliar suas perspectivas políticas de atuação para outras identidades a exemplo das mulheres lésbicas orientadas pelo feminismo e para as travestis.

Em 1990, as travestis organizaram suas próprias pautas instituindo a [ASTRAL] Associação das Travestis e Liberados do Rio de Janeiro incluindo nessa organização as mulheres transexuais e suas pautas. A intenção da 
astral era que a população TT tivesse um diálogo direto com o governo pautando suas próprias demandas.

No ano de 2004 é estabelecido pelo Ministério de Saúde o Comitê Técnico da população GLBT, que ficará responsável pela formulação da política específica do SUS (BRASIL, 2013).

Já em 2003 houve a $12^{\mathrm{a}}$ Conferência Nacional de Saúde, onde a população LGBT foi visibilizada quanto suas demandas (BRASIL, 2004), mas, somente na $13^{\mathrm{a}}$ Conferência em 2008 é que as temáticas de orientação sexual e identidade de gênero surgem no rol das políticas como um aspecto humano que requer atenção de saúde.

$\mathrm{Na} 13^{\mathrm{a}}$ Conferência de Saúde dentre outras deliberações foi demandado: a) a ampliação da participação do movimento LGBT nos Conselhos de Saúde; b) a inclusão dos quesitos de identidade de gênero e de orientação sexual nos formulários e prontuários e sistemas de informação da saúde. c) o aprimoramento do Processo Transexualizador. (BRASIL, 2013).

Em 2005 foi lançado pelo Ministério da Saúde em parceria com ABGLT [Associação Brasileira de gays, lésbicas e transgêneros] o Projeto
SOMOS que consistiu em capacitações de ONG's existentes e estímulo para criação de novas voltadas ao combate a AIDS/ HIV e outras IST's exclusivamente para a população de gays e HSH- homens que fazem sexo com homens, mas, não se intitulam gays.

Em 2008, foi realizada a I Conferência LGBT com a participação de 600 delegados de todos os Estados do Brasil. Na ocasião, desenvolveu-se a Política Nacional LGBT (BRASIL, 2013) que foi aprovada pelo Conselho Nacional de Saúde, desde então, norteando as ações governamentais para e com essa população, a exemplo, do reconhecimento pelo Supremo Tribunal Federal da união homoafetiva, o direito à herança e a adoção de crianças, bem como, o uso do nome social em estabelecimentos públicos de Saúde.

\section{Considerações sobre a Política}

Nacional de Saúde Integral de lésbicas, gays, bissexuais, travestis e transexuais.

O acesso à saúde de qualidade as pessoas travestis e transexuais está pautada no decreto de Lei ${ }^{\circ} 2.836$ de $1^{\circ}$ de dezembro de 2011, trata-se de uma lei 
de responsabilidade do Ministério da Saúde em âmbito federal e das Secretarias de Saúde dos Estados e municípios, de promoverem a saúde da população LGBT de forma universal, integral e equitativa como reza a Constituição Federal no art. $^{\circ}$ III- a Dignidade da Pessoa Humana e no art. $196^{\circ}$ - a Saúde como direito de todos e dever do Estado.

A saúde é um direito social, também compreendido na Constituição Federal (BRASIL, 1988) nos art. 194 e 195 vinculando o desenvolvimento social pleno como o acesso à educação, moradia, trabalho, lazer, esporte, cultura e saneamento básico, uma prerrogativa à promoção da saúde e qualidade de vida da população brasileira.

A lei esboça a preocupação com o cumprimento dos princípios fundamentais do Sistema Único de Saúde [SUS] Lei 8.080 de 19 de setembro de 1990 que reza sobre a universalidade do acesso, a integralidade da atenção e a participação da comunidade, com vistas, a diminuição do processo de exclusão e estigma

\footnotetext{
5 Atualmente o serviço é ofertado em cinco Hospitais Universitários são eles: Hospital das Clinicas da Universidade Federal de Goiás,
}

sociais sofridas pela população LGBT nos serviços de saúde ou pela falta deles.

Esta legislação considera a ampliação do Processo Transexualizador e a disponibilização do tratamento integral de saúde do segmento TT [travestis e transexuais] como: atenção à saúde mental com redução da incidência de alcoolismo, depressão e uso de drogas ilícitas; redução dos danos pelo uso prolongado de fármacos e hormônios sintéticos; redução da mortalidade de travestis; prevenção de cânceres ginecológicos em homens transexuais e de próstata em mulheres transexuais.

No que tange aos objetivos específicos da Política Nacional de Saúde Integral LGBT está descrito a ampliação do desenvolvimento de tecnologias médico- terapêuticas para aprimorar o Processo Transexualizador do [SUS] tendo em vista que as cirurgias de redesignação sexual do feminino para o masculino- metoidioplastia $\mathrm{e}$ neofaloplastia, por exemplo, são realizadas no Brasil de forma experimental nos Centros de Referência de Hospitais Universitários de algumas Universidades Federais ${ }^{5}$.

Goiânia [GO]; Hospital de Clínicas de Porto Alegre, da Universidade Federal do Rio Grande do Sul, em Porto Alegre [RS]; Hospital 
$\mathrm{O}$ risco de morte e debilidade da população TT advém do uso indiscriminado e sem acompanhamento médico de hormônios sintéticos e outros fármacos.

Faz parte da política promover ações de redução de danos já que os resultados do uso prolongado destes expõe o paciente a várias doenças complexas como AVC e Cânceres.

As Travestis e os/as transexuais fazem uso de artifícios farmacológicos para adequação de gênero [hormoneoterapia] que duram em média 2 anos pelo SUS, implantam próteses de silicone, alongam as cordas vocais e reduzem o "Pomo de Adão" para tornar a voz feminina no caso das mulheres transexuais e, usam testosterona sintética, passam pela Mastectomia bilateral com reconstituição aureolar [retirada das glândulas mamárias], histerectomia total e lipoaspiração no caso dos transexuais masculinos. Esses procedimentos médicos são de alto risco e demandam acompanhamento médico específico em todas as etapas (MINISTÉRIO DA SAÚDE, 2013).

Universitário Pedro Ernesto, da Universidade Estadual do Rio de Janeiro [RJ]; Fundação Faculdade de Medicina, da Universidade de São Paulo [USP]; e Hospital das Clínicas da

\section{O atendimento de travestis e} transexuais em hospitais públicos e unidades de saúde em Araguaína-TO.

As diretrizes da Política Nacional de Saúde Integral LGBT trata do atendimento humanizado da população LGBT, considerando todas as formas de discriminação um problema culminante ao processo de adoecimento. Em entrevista uma mulher transexual tece o seguinte relato

\begin{abstract}
Quando fui me consultar com cartão SUS, eles não queriam me atender porque disse que não podiam, tem que fazer ofício, ai eu falei que ia conversar com meu advogado pedir pra ele ligar pra falar a respeito, ai pediu pra aguardar disse que ia ligar na Secretaria da Saúde, eu fiquei aguardando, quando ligaram eu fiquei uns 15 minutos pra ser atendida pelo nome social, é sinal que eles não sabiam da política nacional (Gabriela, 18 anos).
\end{abstract}

$\mathrm{Na}$ fala supracitada a diretriz $\mathrm{n}^{\circ}$ VII (BRASIL, 2013) da Política Nacional de Saúde Integral LGBT em Araguaína parece estar sendo violada ela trata da "Inclusão da temática da orientação sexual e identidade de gênero

Universidade Federal de Pernambuco [UFPE], em Recife [PE]. 
de LGBT's nos processos de educação permanente desenvolvidos pelo SUS".

Esta mesma entrevistada respondeu no questionário relatando não conhecer essa política de saúde. Foram unânimes nos relatos que os profissionais de saúde de Araguaína não estão "preparados" para atender pessoas travestis e transexuais começando pelos recepcionistas que deveriam atende-las utilizando o nome social de acordo com o cartão SUS.

Relatos como o de Jéssica uma trans Cabeleireira relata "meu nome nunca foi respeitado" outro relato de Daniele também Cabeleireira esboça: "sim respeitam, mas, ficam querendo pôr o nome de registro, sempre tem este problema".

Estas falas formam uma percepção que os direitos dessas mulheres não são respeitados enquanto usuárias e que há uma desconexão entre a lei e a prática no ambiente da rede municipal de saúde.

Das cinco mulheres transexuais e travestis que responderam $\mathrm{o}$ questionário, nenhuma faz uso de hormônios acompanhada por equipe médica da rede SUS municipal de Araguaína. Três delas possuem cartão
SUS com nome social conforme a Nota técnica $n^{\circ} 14 / 2014$. Das que não possuem o cartão uma informou que em breve fará e a outra não esboçou desejo.

Sobre a responsabilidade de aplicação da política, nela está descrita três níveis de parceria: a que compete ao Ministério da Saúde [União], as Secretarias Estaduais de Saúde [Estados] e as Secretarias Municipais de Saúde [municípios]. Destaca-se que a fica a cargo da União o apoio técnico e político para a implantação dessa Política em níveis de Estados e Municípios também a distribuição de material de formação de pessoal.

Em resposta ao questionário elaborado nesta pesquisa 0 Superintendente de Atenção Básica de Araguaína, Murilo Bastos, reconhece que no município de Araguaína não há a implementação da Política de Saúde LGBT em âmbito ambulatorial e hospitalar e que não existe a garantia de acompanhamento de equipe multidisciplinar para o atendimento de travestis e transexuais.

No que tange aos Estados fica a seu cargo o apoio técnico aos municípios, além de incluir a Política Nacional de Saúde Integral LGBT nos 
Planos Plurianuais [PPA's], incentivar espaços de promoção da equidade e estimular a representação LGBT nos Conselhos Estaduais e Municipais de Saúde. No Tocantins essa representação está em construção através do estabelecimento do Conselho Estadual da diversidade que atualmente encontrase em discussão.

É de atribuição do município a implantação de fato dessa Política, por meio da identificação das necessidades de saúde da população LGBT, da inclusão no Plano municipal de Saúde, PPA setorial e da articulação com ONG's para melhoria de vida da população LGBT, inclusão da temática étnico-racial e de gênero na formação dos trabalhadores de saúde. Foi verificado que Araguaína-TO não possui até o momento nenhuma parte dessa política implementada.

\section{O Processo Transexualizador e a} promoção da saúde integral das pessoas trans e travestis no Tocantins.

A terapia de "adequação" de gênero no Brasil se dá no âmbito do SUS em Centros Especializados ligados a
Universidades dos grandes centros urbanos no sul e no sudeste.

Mas, o que possibilitou o desenvolvimento de políticas públicas para o segmento transexual foi a patologização dessa identidade na década de 1980 por meio de sua inclusão no DSM [Manual Diagnóstico $e$ Estatísticos de Doenças Mentais] e em 1994 o termo "transexualismo" foi substituído por "transtorno de identidade de gênero".

Corrobora-se com Berenice Bento (2015) em que a transexualidade e as tecnologias médicas são parceiras indissociáveis para a implantação da Política Nacional de Saúde Integral LGBT.

Na década de 1990 houve a regulamentação das atividades médicas relativas ao tratamento de transexuais através de uma Resolução 1482/97 do Conselho Federal de Medicina, onde as atividades relativas ao tratamento de transexuais incluem uma equipe multidisciplinar constituída de um cirurgião reconstrutor genital [urologista/ ginecologista], psiquiatra, psicólogo, endocrinologista, cirurgião plástico, assistente social e enfermeiro. 
ISSN | 2179-7137 | http://periodicos.ufpb.br/ojs2/index.php/ged/index

Em alguns centros de referência existe assessoria jurídica para ajudar nos trâmites da retificação do prenome e gênero principalmente no caso de transexuais operados.

De acordo com a Resolução $n^{\circ} 2$, de 6 de dezembro de 2011 da Comissão de Gestores Tripartite, no qual foi traçado o Plano Operativo da Política Nacional de Saúde Integral LGBT 20122015 o eixo I esboça: O acesso da população LGBT à atenção Integral à Saúde assegura-se a proposta da ampliação do Processo Transexualizador em mais quatro serviços, em atuação estaduais e municipais.

Contudo, o desenho de expansão desse serviço pelo Brasil não é tão animador. O Projeto "Transexualismo" [TX] do Hospital das Clínicas de Goiânia que atendia transexuais e travestis de todo o país provavelmente fechará as portas em breve.

De acordo com a Prof ${ }^{a} \operatorname{Dr}^{a}$ Mariluza Terra Coordenadora do Projeto Tx- Transexualidade, quando perguntada sobre a possibilidade de atendimento de novos pacientes oriundos do Tocantins, relatou que " $\mathrm{O}$ projeto está fechado para novos pacientes, devido à grande fila de espera.
Provavelmente, não abrirá porque estou perto de me aposentar e não consigo ninguém para me substituir".

A situação de pessoas transexuais se reflete em imenso sofrimento psíquico, sentimento de desamparo, depressão, dentre outros processos de exclusão social como o desemprego e a exposição a drogas e a prostituição de forma compulsória.

$\mathrm{Na}$ entrevista realizada com uma transexual e outra pessoa que não se considera transexual nem travesti, mas, que nasceu anatomicamente no sexo masculino, os relatos é que a pior forma de exclusão está na escola e no mercado de trabalho

Muitas vezes eles nem olham pra gente porque o nome no currículo é o de batismo ai não chamam quando vê que é uma travesti. Mesmo a gente sendo preparada, eles não chamam porque a gente é travesti. (Gabriela Rangel. Professora de Dança, 18 anos).

[...] na sociedade é um pouco difícil e constrangedor, igualmente na escola todos me chamavam de Lays, Lays pra cá Lays pra lá...só que tem um professor que ele bateu na mesa não vou chamar de Lays vou chamar de tal né! [...] ai te chamam pelo teu nome? tal fulano! Ai você fala presente! Ai o preconceito reina na sala e as pessoas começam a mangar, sorrir [...]. (Lays Kelly. Estudante, 17 anos).

As falas acima expressam a necessidade de garantir o uso do nome 
social dessas pessoas nos espaços de socialização, mas, como diz (ALMEIDA, 2013) o nome social é um paliativo que não diminui os processos de exposição de pessoas travestis e transexuais a situações humilhantes e vexatórias.

Em resposta a esta demanda o Superintendente de Atenção Básica de Araguaína, Murilo Bastos, relata em questionário que não há garantia do tratamento pelo nome social de travestis e transexuais no âmbito da saúde municipal e que sequer existe um mapeamento dessas pessoas atendidas no Programa Saúde da Família nas Unidades Básicas de Saúde.

$$
\text { Explicita-se nos relatos que o }
$$
apoio da socialização primária, ou seja, da família (Berger, 1966) é preponderante para que os processos de exclusão social decorrentes da vivência da transexualidade sejam minimizados.

\footnotetext{
Muitas travestis quando não tem o apoio da família vão para o mundo da prostituição. Também porque é muito difícil arrumar um emprego, quando não arruma um emprego elas precisam manter o corpo precisa manter a resistência, então graças a Deus, meu pai, minha mãe, meus irmãos, todos me apoiam nunca me abandonaram, então graças a eles eu trabalho desde pequena. No meu trabalho é a moça é a Gabriela e eu não sofro preconceito. (Gabriela Rangel. Professora de Dança, 18 anos).
}

\section{Considerações finais}

Conclui-se neste trabalho que a situação do atendimento de saúde das pessoas travestis e transexuais no município de Araguaína conforme a Política Nacional de Saúde Integral LGBT, não é satisfatória visto que, não existe até o presente momento a implementação dessa política no município.

É notória a vinculação das ações em saúde LGBT promovidas nos dois últimos anos em Araguaína envolvem a questão do combate de IST's/HIV/AIDS, conforme relatado em questionário, houve entrega de preservativos em pontos de prostituição às travestis e transexuais e palestras realizadas neste espectro.

Desta forma, é nítido a violação dos direitos desta população que toma forma na extrema vulnerabilidade social e dificuldade ao acesso de serviços básicos de saúde, pois, não há formação dos profissionais em torno dos direitos que a Política de Saúde Integral LGBT deveria garantir às travestis e transexuais.

Ademais, não existe um material didático produzido pela Secretaria 
Estadual em conjunto com a municipal que inclua essa temática na formação dos trabalhadores de saúde, ou seja, não existe habilitação destes quanto ao tratamento apropriado dispensado à travestis e transexuais, nas Unidades Básicas de Saúde, Unidade de Pronto Atendimento, Hospital Municipal, etc.

Positivamente, pode-se auferir através de questionário que o município de Araguaína-TO, possui um grupo de trabalho no CAPS/AD III- Centro de Assistência Psicossocial Álcool e Drogas, que realiza ações para reduzir os danos causados pela drogadição, alcoolismo, depressão e outras patologias que possam acometer a população de travestis e transexuais.

O que não ficou claro é que, se não existe um mapeamento dessas pessoas no âmbito da Saúde da Família, como esse acompanhamento consegue chegar até o usuário? Com toda controvérsia, ao menos há este grupo de trabalho.

Enfim, por tudo o que foi estudado para realização deste artigo, considera-se insatisfatório o atendimento de saúde das pessoas travestis e transexuais no município de Araguaína, pois, as ações realizadas para garantir- lhes a saúde integral são realizadas de forma isolada- na questão do combate as doenças sexualmente transmissíveis e minimização dos danos de drogas e álcool, que patologiza ainda mais a identidade desses sujeitos e não garante a sua saúde integral- preventiva e curativa, na integralidade como requer a política objeto desse artigo.

\section{Referências bibliográficas}

Almeida, G; Murta, D. Reflexões sobre a possibilidade da despatologização da transexualidade e a necessidade da assistência integral à saúde de transexuais no Brasil. Revista Latino americana de Sexualidad, Salud y Sociedad. n.14, p.380-407, Dossiê n.2, ago. 2013.

BRASIL. Constituição (1988).

Constituição Federativa do Brasil. Brasília, DF: Senado Federal. Centro Gráfico. 1988. 292 p.

BRASIL. Ministério da Saúde. Secretaria de Gestão Estratégica e Participativa. Departamento de Apoio à Gestão Participativa. Política Nacional 
de Saúde Integral de Lésbicas, Gays, Bissexuais, Travestis e Transexuais. Brasília: $1^{\mathrm{a}}$ ed., 2013.

BRASIL. Ministério da Saúde. Secretaria de Gestão Estratégica e Participativa. Departamento de Apoio à Gestão Participativa. Transexualidade e travestilidade na saúde / Ministério da Saúde, Secretaria de Gestão Estratégica e Participativa, Departamento de Apoio à Gestão Participativa. - Brasília: Ministério da Saúde, 2015.

BERGER, Peter; LUCKMANN, Thomas L. A construção social da realidade: Tratado de sociologia do conhecimento. Petrópolis, Editora Vozes, 1973.

BENTO, Berenice. Determinismo biológico revisitado: gênero e raça. Cult (São Paulo), V. único, p. 12-14, 2015.

BENTO, Berenice. Nome social para pessoas trans: cidadania precária e gambiarra legal. Contemporânea Revista de Sociologia da UFSCar, São Carlos, v. único, p. 165-185, 2014.
BUTLER, Judith. Problemas de gênero: feminismo e subversão da identidade. Rio de Janeiro: Civilização Brasileira, 2003.

LOURO, Guacira L. Um Corpo Estranho-Ensaios sobre sexualidade e teoria queer. Belo Horizonte: Autêntica Editora, 2004, 92 p.

SAWAIA, Bader (org.). As artimanhas da exclusão. Petrópolis, Rio de Janeiro: Ed. Vozes, 1999. 